Review of Income and Wealth

Series 0, Number 0, Month 2019

DOI: $10.1111 /$ roiw.12412

\title{
A DIFFERENT PERSPECTIVE ON THE EVOLUTION OF UK INCOME INEQUALITY
}

\author{
By A. B. AtKINSON \\ Nuffield College; London School of Economics \\ AND \\ STEPHEN P. JENKIns* \\ London School of Economics; University of Essex; University of Melbourne; IZA
}

This paper scrutinizes the conventional wisdom about trends in UK income inequality and also places contemporary inequality in a much longer historical perspective. We combine household survey and income tax data to provide better coverage of all income ranges from the bottom to the very top (and make our estimates available to other researchers). We make a case for studying distributions of income between tax units (i.e. not assuming the full income sharing that goes with the use of the household as the unit of analysis) for reasons of principle as well as data harmonization. We present evidence that income inequality in the UK is as least as high today as it was just before the start of World War 2.

JEL Codes: C46, C81, D31

Keywords: Household, Gini coefficient, HBAI, household survey data, income tax data, inequality, SPI, tax unit

\section{INTRODUCTION}

The conventional wisdom is that there has been little change in overall income inequality in the United Kingdom (UK) over the past quarter century. ${ }^{1}$ This picture is based on studies such as those by Cribb et al. (2018) from the Institute for Fiscal Studies (IFS), whose estimated value for the Gini coefficient for equivalized disposable household income in fiscal year 2014/15 is indistinguishable from that for 1990/91 — see the uppermost series in Figure 1. Certainly the changes in recent

Note: We thank Nicolas Hérault for preparing the individual-level income data underlying the estimates that we use from Jenkins (2017). We are grateful to Alissa Goodman (UCL, formerly of the Institute for Fiscal Studies) for providing tax unit micro-data for 1961 to 1999, extending the series of Goodman and Webb (1994), to comments received at the ECINEQ2017 and IARIW2018 conferences especially from Brian Nolan and Joachim Merz, and from two anonymous referees. Jenkins's research is part supported by an Australian Research Council Discovery Grant (award DP150102409, with Richard Burkhauser, Nicolas Hérault, and Roger Wilkins) and core funding of the Research Centre on Micro-Social Change at the Institute for Social and Economic Research by the University of Essex and the UK Economic and Social Research Council (award ES/L009153/1). This paper is based on discussions between the authors in the summer of 2016 and a first draft written by Tony Atkinson. Tony died on New Year's Day 2017, an immense loss to social science and to humanity.

*Correspondence to: Stephen P. Jenkins, Department of Social Policy, London School of Economics and Political Science, Houghton Street, London WC2A 2AE, UK (s.jenkins@lse.ac.uk).

${ }^{1}$ The conventional wisdom has recently been repeated by a Deputy Governor of the Bank of England (Broadbent, 2016).

(C) 2019 The Authors. Review of Income and Wealth published by John Wiley \& Sons Ltd on behalf of International Association for Research in Income and Wealth

This is an open access article under the terms of the Creative Commons Attribution License, which permits use, distribution and reproduction in any medium, provided the original work is properly cited. 


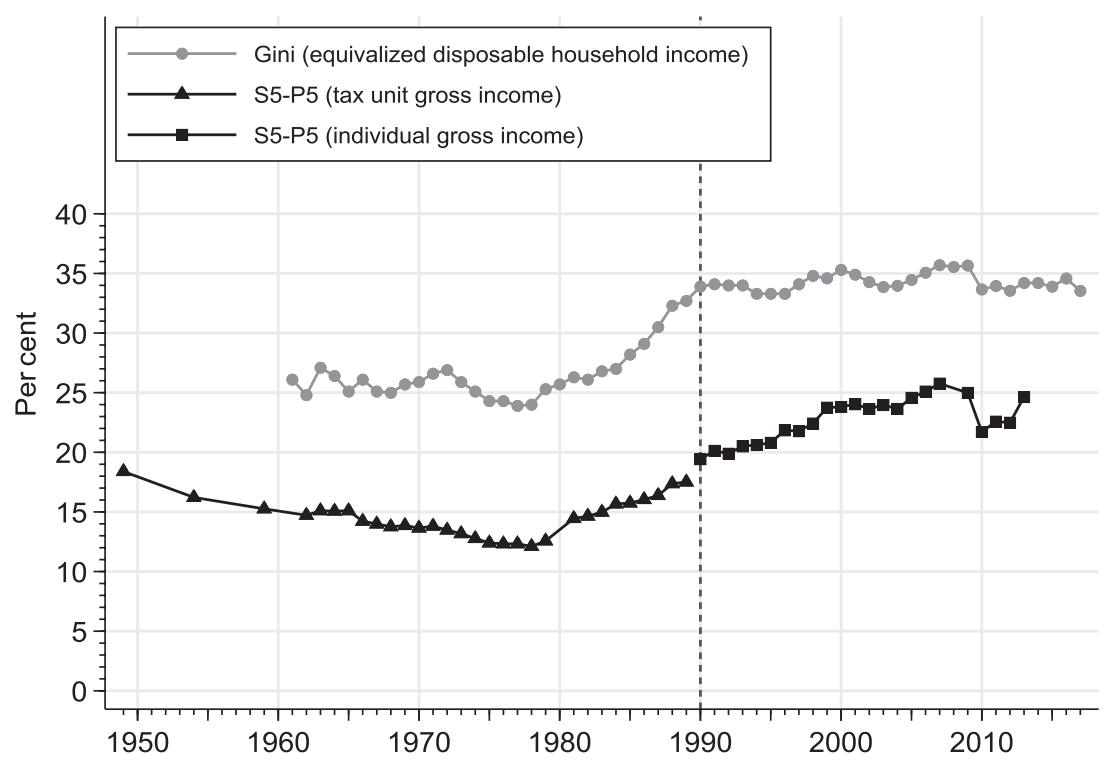

Figure 1. Income Inequality in the UK.

Notes: The Gini series comes from the spreadsheet accompanying Cribb et al. (2018), and is based on the HBAI income series. $S 5-P 5$ is the difference between income share and the population share of the richest 5 percent (where income refers to gross income), and comes from the WID (see Appendix Table A1). It is the between-group inequality term in the decomposition of the Gini shown in eq. (1). Before 1990, the tax unit in the UK was the married couple or the individual; from 1990 it was the individual.

years have been small compared with the 10 percentage point increase in the Gini coefficient that took place between 1978 and 1990.

In this paper, we scrutinize the conventional wisdom about the UK and also place contemporary inequality in a much longer historical perspective - back to just before World War 2. Like the leading annual reports on UK inequality such as by the Department for Work and Pensions ('DWP'; 2018) and the IFS (Cribb et al., 2018), we rely on the Gini coefficient to summarize inequality because the longest series are available for this measure alone. Unlike them, we combine household survey and income tax data in a more systematic way in order to provide better coverage of all income ranges from the bottom to the very top.

The Gini coefficient estimates in Figure 1 are based on annual household surveys, the Family Resources Survey (FRS) from the mid-1990s and the Family Expenditure Survey (FES) before that. DWP statisticians apply a special (but largely undocumented) procedure, the 'SPI adjustment', to a very small number of incomes at the very top of the income distribution using information from income tax data in order to address the problem of securing an adequate response about the incomes of very rich individuals. The tax data are the Survey of Personal Incomes (SPI), a large sample of UK personal income tax records. See Burkhauser et al. (2018a, 2018b) for more details about the SPI and the DWP's SPI adjustment.

The resulting SPI-adjusted data are known as the Households Below Average Income (HBAI) series, and these are used in the annual reports of both the DWP 
and the IFS. As, however, has been demonstrated by Burkhauser et al. (2018a, 2018b) and Jenkins (2017), the conclusions reached about inequality trends may be sensitive to the way in which such top-end adjustments are made, and the authors present a rather different picture of the recent evolution of UK income inequality.

By contrast with the SPI-adjustment approach, Jenkins (2017) uses the household survey data for the bottom $X$ per cent of the population and combines these with data from the SPI for the top $100-X$ per cent. In this way, Jenkins bridges the gap between the survey-based estimates of overall inequality (here measured by the Gini coefficient) and the SPI-based estimates of top income shares reported by the World Inequality Database (WID), employing methods originally developed by Atkinson (2007) and Alvaredo (2011).

Bridging the gap is important, since evidence on top shares indicates that overall inequality in the UK may have increased since 1990. Although real incomes in the bottom and middle ranges of the distribution have been relatively flat (shown by household survey data), top incomes have been rising (shown by tax data). See also Burkhauser et al. (2018a, Figure 1) about this. Combining information from both sources therefore suggests that overall inequality may have been rising.

The effect of a rise in the top income share on overall inequality may be seen from the formula for the decomposition of the Gini coefficient, $G$, when data for two non-overlapping groups - the 'rich' and 'non-rich' - are combined:

$$
G=P_{R} S_{R} G_{R}+P_{N} S_{N} G_{N}+\left(S_{R}-P_{R}\right)
$$

where the subscript $R$ is used for the rich and $N$ for the non-rich, $P$ denotes proportion of the total population and $S$ denotes share of the total income (see Alvaredo, 2011, equation 7, and Jenkins, 2017, equation 6).

The first two terms in (1) represent the contributions to $G$ of within-group inequality, i.e. among the rich and non-rich, respectively. The third term, $S_{R}-P_{R}$, captures between-group inequality, and this is shown in Figure 1 using WID data for the case where the rich are identified as the top 5 percent. That is, $P_{R}$ is fixed at 0.05 , and so changes over time in between-group inequality are driven by changes in $S_{R}$.

Between 1990/91 and 2014/15, the between-group inequality term (derived from WID data) increased by 5 percentage points, and this has a direct effect on total inequality. The rise in the top income share also affects the first two terms in equation (1), thereby moderating the direct effect.

The net effect can be examined by considering the derivative of $G$ with respect to $S$ :

$$
\partial G / \partial S_{R}=1+P_{R} G_{R}-P_{N} G_{N}
$$

If the rich are defined as the top 5 percent, then the second term is less than 0.05 even if $G_{R}$ is 1 . For small $P_{R}$, the expression may be approximated by $1-G_{N}$, which is likely to exceed $1 / 2$ (see below), and so at least half of any increase in $S_{R}$ is likely to be transmitted to $G$. Thus, there are grounds for investigating further the conventional view that UK income inequality has changed little since 1990/91. 
To derive estimates of the overall Gini coefficient using (1), we need to harmonize the data from the household survey and income tax sources. Our first approach is to go from the survey to the tax data definitions, and to build consistently-defined distributions of income among tax units as far as is possible given the data available. We justify this approach and explain how we implement it in Section 2. Our new estimates of how UK inequality has evolved since 1961 are then derived and discussed in Section 3. In Section 4, we show that one may also start with the tax data definitions, and this has the particular advantage that one can link our series for 1961 onwards all the way back to 1937 using the so-called Blue Book estimates of inequality. Section 5 contains a summary and conclusions.

\section{Combining and Harmonizing Income Data from Survey- and Tax-Based Sources}

The series for the Gini coefficient and for inequality between the rich and non-rich shown in Figure 1 are based on different definitions of income, as indicated by the figure legend and notes. Table 1 summarizes the most important definitional differences between the survey-based HBAI and tax-based WID series. We distinguish between definitions of 'income', the income-sharing unit, equivalization for differences in unit size and composition, and the unit of analysis.

Gross income is income from the labor and capital markets plus taxable social security benefits and tax credits. Disposable income is gross income, plus nontaxable social security benefits and tax credits, minus personal income tax payments, employee national insurance contributions, local tax payments, and some other deductions (e.g. employee occupational pension contributions). The unit of assessment for personal taxation in the UK was either a single person or a married couple before 1990, but has been the individual since 1990. A household may contain one or more tax units.

Clearly the survey and tax data sources have to be harmonized in order to be combined. Harmonization could in principle be in either direction: from the survey to the tax data or vice versa. However, the information available in the FRS unit record data is much more detailed.

TABLE 1

Differences in Definitions Between UK TaX- and Survey-Based Income Data

\begin{tabular}{|c|c|c|c|}
\hline Definitional Feature & $\begin{array}{l}\text { Tax-based } \\
\text { WID Data }\end{array}$ & $\begin{array}{l}\text { Survey-based } \\
\text { HBAI Data }\end{array}$ & $\begin{array}{l}\text { Survey-based } \\
\text { IFS Data }\end{array}$ \\
\hline Income & Gross income & Disposable income & $\begin{array}{l}\text { Disposable } \\
\text { income }\end{array}$ \\
\hline Income-sharing unit & Tax unit & Household & Tax unit \\
\hline $\begin{array}{l}\text { Equivalization for differences } \\
\text { in size and composition }\end{array}$ & None & $\begin{array}{l}\text { Modified-OECD } \\
\text { scale }\end{array}$ & None \\
\hline Unit of analysis & Tax unit & Individual & Tax unit \\
\hline Main data source & SPI & FES, FRS & FES, FRS \\
\hline
\end{tabular}

Notes: The series are explained further in the text. In the case of the individual as the unit of analysis, each individual is attributed with the equivalized disposable income of his/her household.

(C) 2019 The Authors. Review of Income and Wealth published by John Wiley \& Sons Ltd on behalf of International Association for Research in Income and Wealth 
We therefore adopt the same procedure as in Jenkins (2017) who adjusted FRS data to a tax data basis for years from 1995/96 to 2010/11, drawing on the data derived and discussed by Burkhauser et al. (2018a). For these years, income is gross individual income. There are no tax data available for tax years 1961/62, $1980 / 81$, or 2008/09. In terms of Table 1, Jenkins (2017) used the same data sources as the 'survey-based HBAI data' but adjusted the data to use the same definitions as employed in the 'tax-based WID data'.

For 1961 to 1999, we make use of data supplied by Alissa Goodman (formerly of the Institute for Fiscal Studies) — what we call the IFS series in Table 1. (The data for 1993 and earlier years are from the FES rather than the FRS but, for brevity, we refer to the survey data collectively as FRS data from now on.) The IFS series we use here refers to distributions of disposable tax unit income among tax units, with no adjustment for differences in tax unit size or composition. The income-sharing unit employed in the data refers to the pre-1990 definition of a tax unit for the years 1990 to 1999 , and therefore the definition is not wholly comparable with that we use for 1995/96 onwards in the Jenkins series. This leads to an unavoidable discontinuity in the time series of our combined-data Gini estimates. There is also the non-comparability introduced by the use of disposable income in the IFS series rather than gross income in the Jenkins series. Unfortunately, the data do not permit full harmonization, and this needs to be kept in mind in what follows. We return to this issue in Section 4.

We report results for the IFS and Jenkins series separately in order to illuminate the impact of the non-comparabilities. The FRS data refer to tax years from 1994/95 and to calendar years before that. For convenience, henceforth we refer to tax year 1994/95 as '1994' and similarly for other years.

Adopting tax data definitions as the reference point may appear to be a backward step. Certainly, ignoring any adjustment for differences in size and composition seems a less satisfactory basis for assessing inequality, although it should be noted that differences in unit size do not apply where the individual is the unit and are less pressing in the case of the tax unit than where the household is the unit of analysis. For many purposes, inequality is best judged in terms of disposable income rather than gross income. The choice of definition for the income-sharing unit is more fundamental, however. The choice of the household in the survey-based HBAI estimates assumes that income is fully shared within the household and that all household members are equally well off. It ignores within-household inequality.

There are therefore good grounds in principle for adopting the individual as the unit of analysis, and for preferring the narrower tax unit to the household. This means reverting to the UK practice of earlier decades when the tax unit was the basis for the analysis of inequality and poverty in the UK. In turn, this makes it possible to link the series directly to studies of inequality before 1961, which is the starting point for the IFS series. The series of Gini coefficients can be taken back to 1937 (see Section 4).

Tax data estimates of top income shares $\left(S_{R}\right)$ require yearly estimates of the population of income units and of the total income held by them (so-called 'control totals). We take both from the WID, and they relate to the UK. The tax unit population from 1990 consists of the total number of individuals aged 15 years and older ('adults'); the tax unit population before 1990 is defined as the total 
number of adults minus the number of married women. The construction of the series for total income is described by Atkinson (2007).

In the survey-based series, there is a disjunction in geographical coverage: before 2003, FRS data relate to Great Britain; from 2003 onwards, they refer to the UK (i.e. Great Britain plus Northern Ireland). However, the effect of the change in coverage on measured inequality is negligible because Northern Ireland's population is very small.

\section{Calculating the Overall Gini Coefficient from 1961 Onwards}

In this section, we explain how we derive yearly estimates of the Gini coefficient using (1), combining tax data information for the first and third components of the equation and survey data information for the second component. We then discuss the new series.

The first two terms in (1) depend on the inequality, measured by the Gini coefficient, within each of the rich and non-rich groups, and on the shares in total income. We take the rich to be the richest 5 percent of the total population: $P_{R}=5$ percent. ${ }^{2}$ Setting $P_{R}$ at this value and $S_{R}=0.4$ (from the WID), the maximum contribution from the first term, arising with a Gini coefficient of 1 , is 4 percentage points. This is much smaller than the third term which with these values would be 30 percentage points, or the second term, which equals $0.54 G_{N}$ or 18 percentage points with $G_{N}=1 / 3$.

This suggests that, while inequality within the rich group is important, the impact on the overall Gini is much less than that of inequality within the non-rich group. Put differently, if, following Jenkins (2017), we assume that the distribution among the rich is Pareto in form, with shape coefficient $\alpha$, then it may be sufficient to apply the Pareto coefficients implied by the WID data to arrive at $G_{R}$ via the formula $G_{R}=1 /(2 \alpha-1)$.

Appendix Table A1 (in spreadsheet form in the Supporting Material) contains the WID estimates of the income share of the top 5 per cent in column 1, the estimated Pareto coefficient $(\alpha)$ and value of $G_{R}$ in columns 2 and 3. We computed the Pareto coefficients using top income share estimates. As a rule we estimated them from the top 0.1 per cent share $(S 0.001)$ within the top 1 per cent share $(S 0.01)$ : $\alpha=1 /[1-\log (S 0.01 / S 0.001) / \log (10)]{ }^{3}$ When the top 0.1 per cent shares were not available, we used the closest substitutes. The WID estimates cover the period from 1918 but we concentrate on the last 50 years.

The Gini coefficient among the rich was 28 percent in 1962, fell to around 20 percent at the end of the 1970 s, and then reversed, rising to 30 percent at the end of the 1980s and being over 40 percent in four of the last 7 years.

\footnotetext{
${ }^{2}$ Jenkins (2017) undertook his analysis using $P_{R}$ values of 1 percent, 5 percent, and 10 percent (after examination of survey under-coverage of top incomes), and he shows that overall estimates are insensitive to the choice. We think it implausible to think of the rich as encompassing more than the top 10 percent.

${ }^{3}$ The issue of how best to estimate the Pareto coefficient describing the shape of the distribution at the top (specifically the issue of which top income threshold to use) is different from the issue of choosing the top income group for combined data analysis (the top 5 percent here). On the first issue, Jenkins (2017) shows that a relatively high threshold - much higher than those often used - is required to derive reliable estimates of the Pareto coefficient.
} 
The estimates for 2009 onwards, which partly reflect the effects of the recession and global financial crisis beginning in 2008, must also be interpreted in the light of changes in income-reporting behavior by high-income tax-payers in response to changes in the top rate of income tax announced by successive UK governments. In March 2009, i.e. just before the start of the 2009/10 tax year, the Labour Government announced that the top marginal tax rate was to be raised from 40 to 50 percent with effect from April 2010 (the start of the 2010/11 tax year) providing incentives to top-rate taxpayers to report income in 2009/10 rather than later. This led to 'considerable forestalling' of income (Seely, 2014). In March 2012, i.e. just before the start of the 2012/13 tax year, the Conservative Government announced that the top rate was to be reduced to 45 per cent with effect from April 2013 (the start of the 2013/14 tax year), which again provided an incentive for income to be moved between tax years, in that case from 2012/13 to 2013/14.

From the information about the rich group, we can calculate the contribution to overall inequality of the first term in equation (1). Defining the rich to be the top 5 per cent, the contribution in the early 1960 s is less than 0.3 percentage points. It rises to around 0.6 percentage points in the most recent years but remains modest compared with the 10 percentage point increase in $G$ since 1978 shown in Figure 1. The contribution is greater using the tax data than would be the case if the estimate were based on the Gini coefficient for the top 5 per cent from the IFS data (Table A1, column 4), where $G_{R}$ is on average some 8 percentage points lower. But the resulting difference is small.

The action in terms of inequality trends comes mostly from the second and third terms in (1) - the maximum value of the first term is only 0.68 per cent. The Gini coefficients for the bottom 95 percent according to the IFS and Jenkins data are shown in Appendix Table A1 (columns 6, 6a), from which we derive the second term in (1) for 1961-1999 and 1994-2012 respectively (columns 7, 7a).

Adding the third term - summarizing inequality between the rich and nonrich groups - gives the 'combined data' Gini coefficients shown in Appendix Table A1 (columns 9, 9a). These Ginis are plotted in Figure 2, together with the contributions from the second and third terms in equation (1).

Two conclusions emerge. The first is the dominant role played by the share of the top 5 percent. It is the between-group component that drives much of the change over time in the combined-data Gini, both when inequality was falling in the 1960s and 1970s and when it rose after 1979. ${ }^{4}$ Moreover, its contribution to overall inequality rose over time: from just over a third in 1961 to around a half in 2009. Inequality within the bottom 95 percent did contribute to the rise in inequality in the 1980s but the effect was modest.

The second conclusion is that, as represented by these estimates, the period since 1990 cannot be described as one of 'stability' - except in relation to the substantial increase in inequality during the 1980s. The IFS series estimate of the Gini increased by two percentage points between 1990 and 1999. And the Jenkins series shows a further one percentage point increase between 2000 and the eve of the

\footnotetext{
${ }^{4}$ Our conclusions, based on times series data for a single country, are consistent with Leigh's conclusion based on country-panel data that there is a 'strong and significant relationship between top income shares and broader inequality measures, such as the Gini coefficient' (2007, F619).
} 


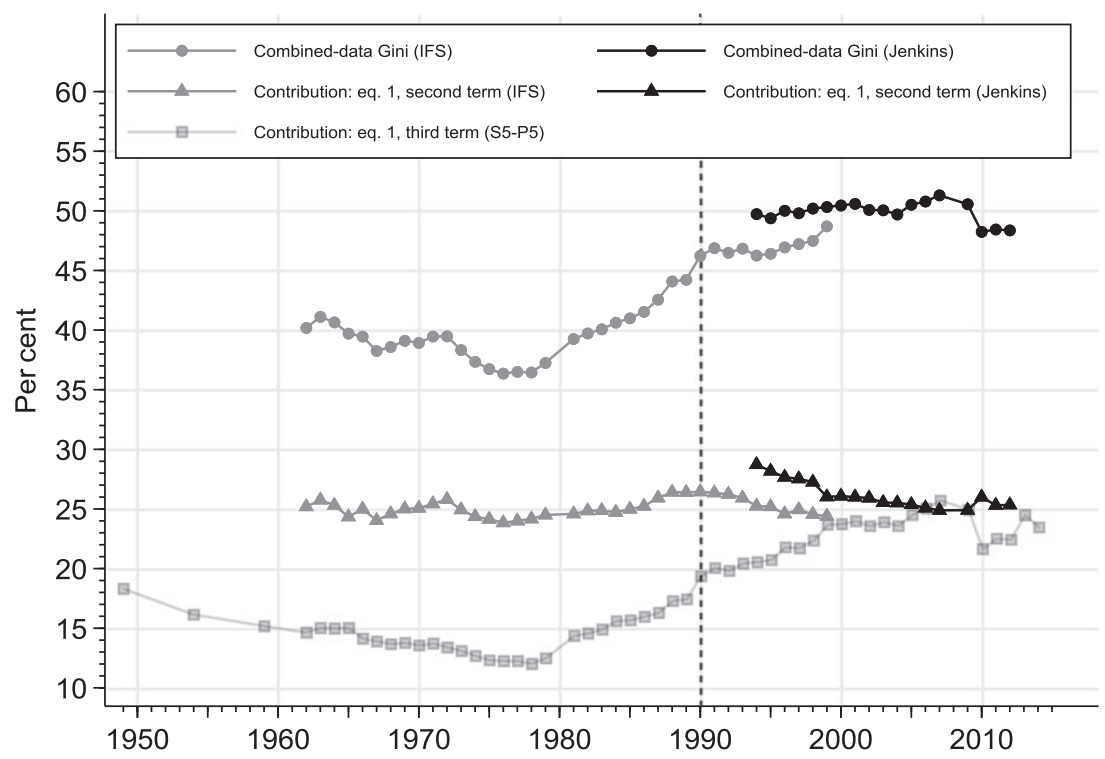

Figure 2. Combined-Data Gini Coefficients, 1961-2012, and Within- and Between-Group Inequality Contributions.

Notes: The two combined-data Gini coefficient series are calculated using eq. 1 and use data for the poorest 95 percent from the IFS series for 1961-1991 and Jenkins (2017) for 1994-2012. (See Appendix Table A1.) Data for the richest 5 per cent come from the WID. See the text for details.

global financial crisis and UK recession, 2007. There is more of an upward trend to inequality among tax units over the whole period than is shown by the Gini for equivalized household income (Figure 1). The conventional wisdom that we cited in the Introduction-UK income inequality has been broadly unchanged since the start of the 1990s - therefore needs some revision or at least qualification.

Differences from the conventional wisdom arise because we use a different income-sharing unit (tax unit) and take greater account of survey under-coverage of top incomes. The choice of inequality measure is also relevant. Blundell et al. (2018, especially Figure 2) examine UK income inequality using the pre-1990 tax unit as the income-sharing unit (as in the IFS series) and report almost no change in inequality from the mid-1990s onwards. Their result is not inconsistent with ours, however, because they summarize inequality in terms of the ratio of the $90^{\text {th }}$ percentile to the $10^{\text {th }}$ percentile, and so income changes for top-income earners cannot affect their results. ${ }^{5}$ By contrast, the Gini coefficient we use is calculated using data on all incomes, from the lowest to the highest, but is a middle-sensitive measure. If we had used a more top-sensitive inequality index, the upward trend in inequality would be even greater than as shown for the combined-data Gini coefficients displayed in Figure 2. See Burkhauser (2018a) and Jenkins (2017) for illustrations of this point.

${ }^{5}$ Blundell et al. (2018) also restrict attention to tax units headed by individuals aged 25-55 years, and 'income' is disposable income equivalised using the modified-OECD scale. 


\section{Turning the Tables: Starting from the Tax Data and Going Back to 1937}

The estimates presented so far have started from the position that the household survey is the primary source, and the tax data are brought into play to correct for the incomplete coverage of top incomes in the survey. However, the SPI tax data do extend to much of the population, and one could approach the issue of how to summarize inequality as one of starting from the tax data and introducing evidence from survey sources to correct for the non-coverage of those outside the tax statistics.

In this section we use published inequality estimates based on this second approach, which is the method adopted in the past in the UK's 'Blue Book' series. ${ }^{6}$ (The Blue Book label refers to the fact that the estimates were originally published annually in National Income and Expenditure, known as the Blue Book.) For a number of years from 1949, Gini coefficient estimates were derived from distributions of income in which SPI data were supplemented with additional information on the incomes of non-taxpayers and on sources of income not available to the tax authorities (mainly non-taxable income and investment income taxed at source). ${ }^{7}$ Among the sources employed in the more recent years was the FES. The Blue Book estimates were discontinued in 1969 but revived in the mid-1970s as a result of the work of the Royal Commission on the Distribution of Income and Wealth. The estimates were published in Economic Trends, the last version appearing in November 1987, with estimates for 1984/85. For 1937, no SPI data were available but the Royal Commission on the Distribution of Income and Wealth (1979) derived a Blue Book-type Gini coefficient from taxpayer incomes reported on tax returns for the 1937/38 tax year and estimates of the population and income control totals and the incomes of non-taxpayers.

Derivation of the Blue Book series of Gini coefficients makes substantial use of the tax data income distributions, applying adjustments to them that have no counterpart in the series constructed in the previous section, and there is correspondingly much less input from the survey data. The coverage of the population of tax units by the SPI was typically between 70 and 80 percent, implying that around 20 to 30 percent is filled in from the other sources (including survey data) and mainly at the bottom of the income range. Ramprakash (1975) provides a detailed discussion of the methods and sources used.

The Blue Book estimates of the Gini coefficient refer to distributions among tax units, and are available for both gross income and also income after deduction of income tax. As such, the Blue Book series are-unlike the HBAI series - close to the tax unit series constructed in the previous section, which suggests that we can link the results from 1961 backwards to the earlier Blue Book estimates. ${ }^{8}$

The estimates from the various inequality series are shown in Figure 3. The Blue Book Ginis for after-tax income are lower than the combined-data Ginis based on the IFS series estimate in the years where they overlap, reflecting the fact

${ }^{6}$ The second approach is also used by the more recent DINA project (Alvaredo et al., 2016).

${ }^{7}$ Blue Book estimates of other summary inequality measures are unavailable.

${ }^{8}$ The years covered by the Blue Book estimates are 1937, 1949, 1954, 1959, 1962 to 1967, 1968/69 to $1978 / 79,1981 / 82$ and 1984/85. Estimates have been published for some other years in the 1950s and 1960 s, but these are based on extrapolations of earlier surveys and cannot be considered reliable (Stark, 1978, 49). 


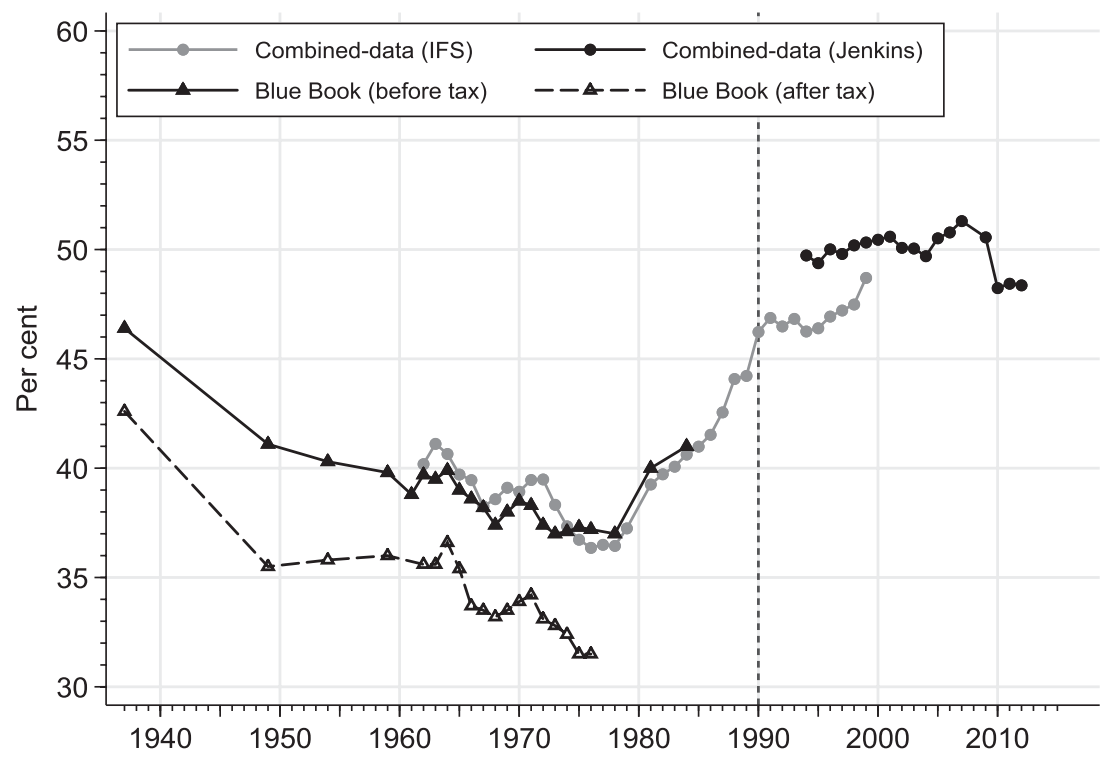

Figure 3. UK Inequality, 1937-2012: Combined-Data and Blue Book Gini Coefficients.

Notes: The combined-data Gini coefficient series are calculated using equation 1 and use data for the poorest 95 percent from the IFS series for 1961-1991 and Jenkins (2017) for 1994-2012. (See Appendix Table A1.) The Blue Book series are discussed in the text.

that the IFS survey-based series has better coverage of the bottom of the income distribution than the Blue Book series. ${ }^{9}$ However, Figure 3 also shows that the two Blue Book series move in parallel. Moreover, importantly for linking series over time and noting the unavoidable data non-comparabilities cited earlier, the Blue Book and IFS series change from one year to the next in similar fashion over the years that the series overlap.

In sum, there is some justification for treating the Gini estimates as a continuous series and linking back to 1937 , generating a series that spans three-quarters of a century.

Figure 4 shows four such linked series, each constructed from the series shown in Figure 3 using different approaches to the non-comparability issues that we have referred to. For reference, the share of top 5 per cent is also shown. Series 1 is constructed by linking together the Blue Book and Jenkins series of Gini coefficients. These two series are the most harmonized with each other of all the series shown in Figure 3. Both are based on distributions of tax unit gross income (though that definition changed in 1990; see above). Clearly, there is a period from the mid1980s to the mid-1990s for which series 1 provides no estimates, but this is no disadvantage given the goal of comparing inequality levels eight decades apart.

${ }^{9}$ The lower inequality shown by the Blue Book series is not due to differences in income definition. The disposable income definition underlying the IFS series includes more deductions (e.g. for employee national insurance contributions and local taxes) than does the after-tax income definition underlying the Blue Book series. Other things equal, one would expect this difference to lead to lower inequality in the IFS series. 


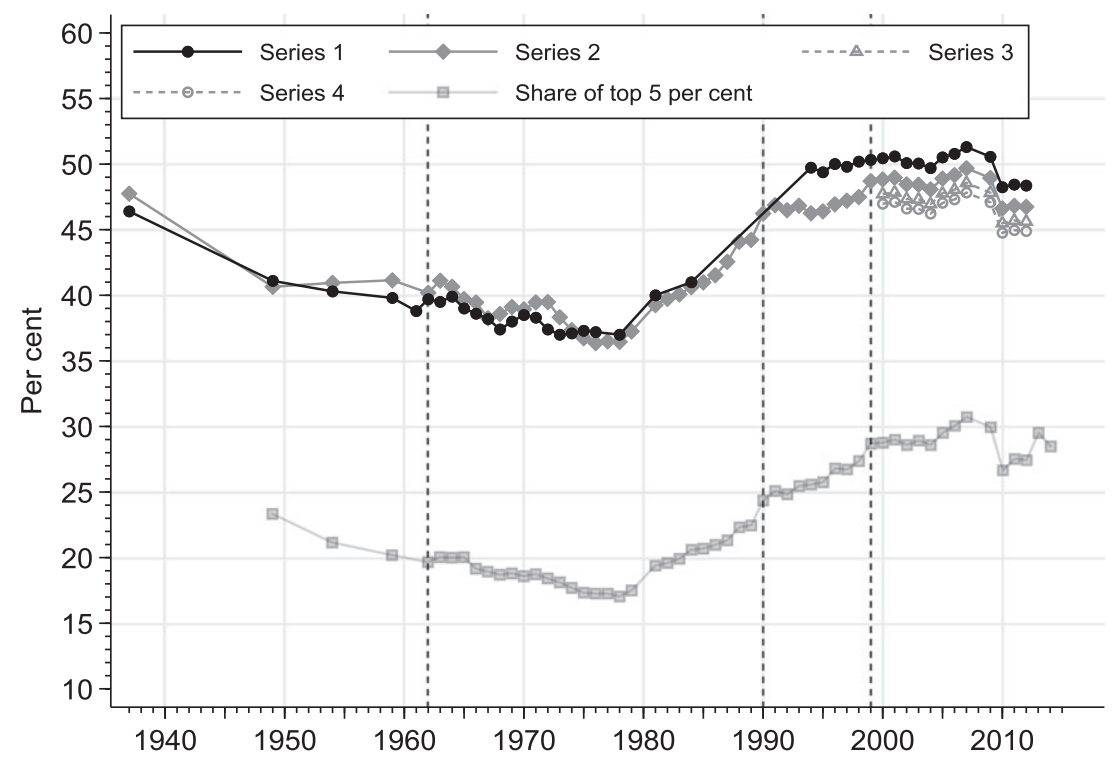

Figure 4. Gini Coefficients (Linked Series) and Share of Top 5 percent, 1937-2012.

Notes: The Gini coefficient series are constructed by linking together series shown in Figure 3. Series 1 is our preferred series. The dashed lines for 1962 and 1999 represent seam years in the construction of series 2-4. Series 3 and 4 differ from Series 2 from 1999 onwards only. Before 1990, the tax unit in the UK was the married couple or the individual; from 1990 it was the individual. Data for the richest 5 percent come from the WID (Appendix Table A1). See the text for details.

Series 1 is our preferred linked series on harmonization grounds but, in order to check the sensitivity of any conclusions that we draw from it, we also construct alternative series. Series 2-4 are each variants of an approach in which we start with the IFS series covering 1961-1999 and link other series to it. The IFS series is based on tax unit (pre-1990 definition) disposable income. For the years prior to 1961, we link this with the Blue Book after-tax income series by shifting up the Blue Book series by 5.1 percentage points. This is the average difference between the two series of Gini coefficients for the years in which they overlap, and we note that the series move broadly in parallel over the same years (there is little variation around the average gap). This yields common values for series $2-4$ over the period 1937-1999. The only combined-data series continuing after the IFS one is the Jenkins series which is based on individual gross income. The main issue for linking the two series is that redistribution as commonly measured fell over the period for which they overlap (the mid-1990s): the Gini coefficients for gross and disposable income do not move in parallel. ${ }^{10}$ We derive series 2 for the post- 1999 period by shifting the Jenkins series values after 1999 down by the gap between the series in 1999 (1.6 percentage points), series 3 by shifting the Jenkins series down by the average gap between 1994 and 1999, and series 4 by shifting the Jenkins series down

\footnotetext{
${ }^{10}$ The gaps between the Ginis for equivalised household gross income and equivalised household disposable income also do not move in parallel over the same period. See Office for National Statistics (2018, Figure 12) and associated spreadsheet.
} 
by the gap in 1994 (3.5 percentage points). Thus series $2-4$ cover the range of potential outcomes for the post-1999 period.

The linked series shown in Figure 4 give rise to two conclusions. The first conclusion is that income inequality in contemporary UK is at around the same level or higher than found in pre-war Britain.

According to series 1, our preferred series, contemporary inequality is unambiguously higher. By 1995, the Gini coefficient in the UK was three percentage points higher than the level recorded for 1937 (46.4 percent) and, subsequently, inequality rose further to a peak around the onset of the crisis. Although inequality fell back slightly in the post-crisis years - for reasons that are difficult to interpret (see Section 3) - the Gini coefficient for 2012, 48.4 per cent, was still at a higher level than 75 years earlier, in 1937. The sensitivity checks provided by linked series 2-4 suggest that contemporary inequality may not be higher today than in 1937, but perhaps at around the same level. Gazeley et al. (2017) have argued that the Royal Commission's (1979) estimate of the post-tax Gini coefficient for 1937 is too high. To the extent that this claim is true and also applies to the pre-tax Gini, there is more evidence that contemporary income inequality is higher than in 1937.

The second conclusion is that the overall level of inequality follows closely the time path of the share of the top 5 percent - a finding already apparent from Figure 1. Top income shares may therefore provide an important leading indicator for changes in overall inequality. The latest version of the WID data, released after we had completed our analysis, provides two new estimates of the income share of the top 5 percent, of 29.6 percent for 2013 and 28.5 percent for 2014, and these are around 2 percentage points higher than the corresponding estimates for the three previous years. Earlier we argued that at least half of any increase in $S_{R}$ is likely to be transmitted to the overall Gini coefficient. Hence the latest WID estimates for $S 5$ suggest that inequality in 2013 and 2014 may be at least 1 percentage point higher than in 2012 (the latest year for which combined-data estimates are currently available), i.e. putting into reverse the earlier post-crisis decline in inequality followed by stability between 2010 and 2012. This projected increase represents another potential departure from the conventional wisdom encapsulated by the HBAI series shown in Figure 1-the HBAI inequality trend is relatively flat. The increase also reinforces the conclusion that inequality is at least as high today as it was in 1937.

\section{Summary and Conclusions}

This paper provides a perspective on the evolution of UK income inequality that differs in two major respects from that usually presented. First, it combines distributional data from two sources - surveys and tax records - in a different way from the HBAI series that is the main reference point for public discourse about income inequality trends in the UK. Second, it does not assume the full income-sharing that goes with the use of the household as the unit of analysis. The distribution studied here is between tax units (families) or, since 1990, individuals.

We appreciate that such a perspective is not to everyone's taste. There are good grounds for considering inequality in terms of disposable income, not gross 
income, and for allowing via equivalization for differences in unit composition. However, analysis of the gross income distribution is a vehicle for understanding the determinants of ultimate inequality. Moreover, reliance on household-based estimates risks obscuring within-household inequality. The UK used to measure income inequality and poverty in terms of the family unit, and this was for good reasons. Furthermore, it allows us to link to the earlier studies, going back to 1937, setting the contemporary estimates in a long-run historical context. In addition, up-to-date estimates of top income shares may provide leading indicators for changes in the overall (combined-data) Gini coefficient.

Clearly, there are some non-comparabilities in the series definitions that we have used, implying that our estimates need to be treated with appropriate caution. However, it appears reasonable to argue that income inequality in the UK today is at least as high as it was just before World War 2 .

\section{REFERENCES}

Alvaredo, F., "A Note on the Relationship between Top Income Shares and the Gini Coefficient," Economics Letters, 110, 274-7, 2011.

Alvaredo, F., A. B. Atkinson, L. Chancel, T. Piketty, E. Saez, and G. Zucman, "Distributional National Accounts (DINA) Guidelines: Concepts and Methods Used in WID.world," WID.world Working Paper 2016/1, Paris School of Economics, Paris, 2016.

Atkinson, A. B., "Measuring Top Incomes: Methodological Issues," in A. B. Atkinson, and T. Piketty (eds), Top Incomes over the Twentieth Century: A Contrast Between Continental European and English-Speaking Countries. Oxford University Press, Oxford, 2007.

Blundell, R., R. Joyce, A. Norris Keillor, and J. Ziliak, "Income Inequality and the Labour Market in Britain and the US," Journal of Public Economics, 162, 48-62, 2018.

Broadbent, B. "The Distributional Implications of Low Structural Interest Rates and Some Remarks about Monetary Policy Trade-Offs", Speech given at the Society of Business Economists Annual Conference, November 18, 2016.

Burkhauser, R., N. Hérault, S. P. Jenkins, and R. Wilkins, "Top Incomes and Inequality in the UK: Reconciling Estimates from Household Survey and Tax Return Data," Oxford Economic Papers, 70, 301-26, 2018a.

"Survey Under-Coverage of Top Incomes and Estimation of Inequality: What is the Role of the UK's SPI Adjustment?," Fiscal Studies, 39, 213-40, 2018b.

Cribb, J., A. Norris Keiller, and T. Waters, Living Standards Poverty and Inequality in the UK: 2018. Institute for Fiscal Studies, London, 2018.

Department for Work and Pensions, Households below Average Income. An Analysis of the Income Distribution 1994/95 - 2016/17, Department for Work and Pensions, London, 2018.

Gazeley, I., A. Newell, K. Reynolds, and H. Rufrancos, "What Really Happened to British Inequality in the Early $20^{\text {th }}$ Century? Evidence from National Household Expenditure Surveys 1904-1961", Discussion Paper 11071. IZA, Bonn, 2017.

Goodman, A., and S. Webb, For Richer, for Poorer: The Changing Distribution of Income in the United Kingdom, 1961-91, Commentary 42, Institute for Fiscal Studies, London, 1994.

Jenkins, S. P., "Pareto Models Top Incomes, and Recent Trends in UK Income Inequality," Economica, 84, 261-89, 2017.

Leigh, A., "How Closely do Top Income Shares Track Other Measures of Inequality?," Economic Journal, 117, F619-F633, 2007.

Office for National Statistics, Effects of Taxes and Benefits on UK Household Income: Financial Year ending 2016, Office for National Statistics, London, 2018.

Ramprakash, D., "Distribution of Income Statistics for the United Kingdom, 1972/73: Sources and Methods," Economic Trends, 262, 78-95, 1975.

Royal Commission on the Distribution of Income and Wealth, Fourth Report on the Standing Reference, Cmnd 7595, Her Majesty's Stationery Office, London, 1979.

Seely, A., Income Tax: The Additional $50 p$ Rate, Standard Note SN 249, House of Commons Library, London, 2014.

(C) 2019 The Authors. Review of Income and Wealth published by John Wiley \& Sons Ltd on behalf of International Association for Research in Income and Wealth 
Stark, T., The Distribution of Personal Income in the United Kingdom 1949-1963, Cambridge University Press, Cambridge, 1978.

World Inequality Database. https://wid.world/.

\section{SUPPORTING INFORMATION}

Additional supporting information may be found in the online version of this article at the publisher's web site:

Table A.1: The Combined-Data Gini Coefficient, and its Components, 1961-2012 